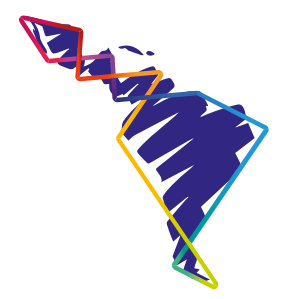

\title{
Infancia, derechos humanos y ciudadanía
}

\section{Childhood, human rights and citizenship}

\author{
Sergio Ruiz Díaz Arce ${ }^{1}$
}

\section{Resumen}

Si bien el escenario jurídico de la infancia después del advenimiento de la Convención Internacional sobre los Derechos del Niño ha generado un impacto en las legislaciones nacionales, el ejercicio de esos derechos por parte de sus titulares continúa presentado algunas restricciones. En este sentido, el presente artículo tiene como objetivo realizar un análisis sobre el cambio de paradigma en la infancia asociada a la noción de ciudadanía, la cual es entendida como un proceso de afirmación y conquista de derechos. Para ello, se parte de una antigua concepción de protección que consideraba a la persona menor de edad como un ser incapaz e incompleto, en contraste con un nuevo paradigma de protección, resultado de las nuevas leyes para la infancia y la condición de sujeto de derechos. En este contexto, la ciudadanía de la infancia es entendida en contraposición a la idea de "futuros ciudadanos", tomando como fundamento los derechos que fueron adquiridos, entre ellos el de participar y ser actores sociales, conforme al desarrollo de la autonomía progresiva. Por tanto, se considera necesario afirmar la ciudadanía de la infancia por medio del principio de autonomía progresiva, para alcanzar la igualdad de derechos entre las personas y lograr construir sociedades más democráticas.

Palabras clave: Derechos del niño, ciudadanía, paradigmas, autonomía progresiva.

\section{Summary}

Although the legal scenario for children after the advent of the International Convention on the Rights of the Child has generated an impact on national laws, the exercise of these rights by their holders continues to present some restrictions. In this sense, the present article aims to perform an analysis on the paradigm shift in childhood as associated to the notion of citizenship, which is understood as a process of affirmation and conquest of rights. Thence, the analysis initiates from an old conception of protection that considered the minor as an incapable and incomplete being, in contrast to a new protection paradigm, resulting from new

1 Abogado por la Universidad Nacional de Asunción. Magíster en Derecho por la Universidad de Brasilia. Desarrolla investigación de Doctorado en el Programa de Pos-Graduación en Derecho de la Universidad de Brasilia. Integra el grupo de investigación Retórica, Argumentación y Juridicidades - GPRAJ. 
laws for children and their condition as holders of rights. In this context, childhood citizenship is understood as opposed to the idea of "future citizens", based on the rights that were acquired, including the right to participate and be social actors, in accordance with the development of progressive autonomy. Therefore, it is considered necessary to affirm the citizenship of children through the principle of progressive autonomy in order to achieve equal rights among people and build more democratic societies.

Keywords: Children's rights; Citizenship; Paradigms; Progressive autonomy.

\section{Introducción}

La relación entre infancia y ciudadanía en un contexto de Estado democrático de derecho puede caracterizarse de manera somera como un proceso de conquista inacabado. En este sentido, si bien la infancia como grupo históricamente excluido ha sido uno de los últimos invitados a la mesa de la ciudadanía, su participación dentro de la sociedad continúa dándose de forma limitada. Así, la noción de ciudadanía puede ser entendida como un status que fue conquistado por los miembros de pleno derecho de una comunidad, quienes son iguales en lo que se refiere a los derechos y deberes que implica (Marshall, 1967).

En cuanto a la realización de ciudadanía, esta no puede ser entendida apenas como un consenso definitivo dentro de la sociedad, debido a que los conflictos de intereses entre los individuos se sobrevienen de forma constante. Por consiguiente, existen situaciones en que los individuos se dividen entre aquellos que defienden el statu quo, y por el otro, quienes luchan contra las injusticias, reclaman derechos e intentan cambiar el rumbo de la historia (Demo, 1941).

Para el mundo de la infancia, la idea de ciudadanía comienza a aparecer más próxima luego de la aprobación de la Convención Internacional de los Derechos del Niño (CDN) en 1989, la cual marca el inicio de un cambio de paradigma para los niños, niñas y adolescentes (NNA), quienes pasan a adquirir el estatus de sujeto de derechos. A partir del referido marco legal, se abandona el sistema de situación irregular para adoptar un sistema de protección integral, instalando así un nuevo paradigma en la mirada del Estado hacia NNA como sujetos activos de sus derechos en todos los ámbitos en los cuales se desenvuelven. Para la bibliografía regional (García, 1990; García, 1992; García, 1994; García, 1997a; Beloff, 2009), algunas de las diferencias esenciales entre la doctrina de la situación irregular y la doctrina de la protección integral marcan, de manera profunda, el nuevo paradigma de la niñez.

Esta confirmación del estatus de NNA como sujetos de derechos, condición inherente a toda persona humana, lleva también implícito consecuencias que 
trascienden el ámbito meramente jurídico. Así, el reconocimiento de esta condición constituye el punto de partida para la reflexión y el análisis sobre la situación de NNA y, su lugar en la sociedad. De esta manera, el nuevo paradigma supone un abandono de antiguas prácticas vinculadas a la infancia, mediante una concepción que los incluye en la categoría de "persona", presentándonos a los NNA como seres humanos libres y en igualdad de derechos. Es decir, un grupo de personas con derechos que se ubican en el mismo nivel que las personas adultas, salvo la condición natural de evolución en que se encuentran y que conlleva una responsabilidad del Estado y de la sociedad ${ }^{2}$.

Sin embargo, el paso de un paradigma a otro parece ser una transición inacabada en nuestras sociedades latinoamericanas. Los vestigios del antiguo paradigma continúan presentes, no solamente en el imaginario colectivo, sino también en ciertas prácticas provenientes de las instituciones del Estado, especialmente de la administración de justicia, que se aferran a una concepción jurídicamente superada, pero socialmente presente, que no reconoce a la infancia como grupo social con derechos dentro de la sociedad.

Ahora bien, si la condición de persona sujeto de derechos fue concebida como un mecanismo para lograr la inclusión social y superar el paradigma tradicional, donde la infancia era considerada apenas como objeto de protección y cuyos derechos se reducían a la voluntad de las personas adultas, ¿por qué los NNA continúan siendo un grupo de personas con limitaciones para el ejercicio de sus derechos, a pesar de haber obtenido protección y reconocimiento jurídico dentro de la sociedad?

La hipótesis planteada es que la concepción de infancia como sujeto de derechos está estrechamente vinculada a la noción de ciudadanía. No obstante, el estatus de ciudadano o ciudadana de los NNA no cuenta con un reconocimiento dentro de la sociedad, como ha acontecido con otros grupos excluidos, debido a la acción dominante ejercida por el mundo adulto que niega la condición de ciudadanía a la infancia. Por lo tanto, se hace necesaria la afirmación de la persona menor de edad como ciudadana del presente y no como un proyecto futuro, para que el ejercicio de derechos y su participación en ellos puedan darse de forma plena.

Para comprobar dicha hipótesis se analizará la transición hacia el nuevo paradigma y su construcción conforme una revisión histórica asociada a la idea de ciudadanía,

2 "Los Estados Partes respetarán las responsabilidades, los derechos y los deberes de los padres o, en su caso, de los miembros de la familia ampliada o de la comunidad, según establezca la costumbre local, de los tutores u otras personas encargadas legalmente del niño de impartirle, en consonancia con la evolución de sus facultades, dirección y orientación apropiadas para que el niño ejerza los derechos reconocidos en la presente Convención” (CDN, 1989, artículo 5). 
con el objetivo de medir el grado de avance de ambos conceptos (infancia y ciudadanía). Para ello, se tomará como punto de referencia importante la CDN, que constituye un hito revolucionario en la lucha por los derechos de la infancia y ha marcado, sin dudas, el proceso de construcción para una nueva concepción de la infancia a partir de un nuevo paradigma.

\section{Un cambio de paradigma}

Thomas Kuhn (1971) propone un enfoque que permite la comprensión desde una perspectiva histórica acerca de los cambios que se han producido en la ciencia a lo largo del tiempo. Así, este autor concibe el desarrollo de la ciencia como una continua sucesión de soluciones a la tensión esencial que se da entre fuerzas conservadoras, orientadas hacia la permanencia, y fuerzas innovadoras, dirigidas hacia el cambio, a lo que él mismo denomina como paradigma: “... realizaciones científicas universalmente reconocidas que, durante cierto tiempo, proporcionan modelos de problemas y soluciones a una comunidad científica" (Kuhn, 1971, p. 13).

Para un mejor abordaje, es posible delimitar el concepto de paradigma en relación con un aspecto sociológico, que hace referencia a la comunidad científica que la asume. De esta manera, se tiene un aspecto histórico, sobre el reconocimiento de una vigencia en el tiempo; un aspecto consensual, es decir, una exigencia consensual institucionalizada, lo cual alude a la necesidad de aceptación general; y, finalmente, un aspecto prescriptivo sobre las normas de actuación convenidas y regulaciones mediante las cuales los miembros de la comunidad científica suscriben un determinado paradigma. Sin embargo, según este autor, cualquier paradigma es incompleto y susceptible al cambio, pudiendo inclusive producirse una crisis, requisito previo para una revolución.

Un buen número de críticos han dudado de que una crisis, la observación común de que algo anda mal, preceda tan invariablemente las revoluciones como yo lo he dicho, implícitamente, en mi texto original. Sin embargo, nada de importancia en mi argumento depende de que las crisis sean un requisito absoluto para la revolución. Tan solo necesitan ser el preludio habitual, que aporte, por decirlo así, un mecanismo de auto-corrección que asegure que la rigidez de la ciencia normal no siga indefinidamente sin ser puesta en duda. (Kuhn, 1971, p. 278)

En cuanto a las revoluciones políticas, estas se producen cuando las instituciones existentes han dejado de satisfacer adecuadamente los problemas planteados por el medio ambiente que ha contribuido en parte a crearla. De igual manera, las revoluciones científicas se inician cuando un paradigma existente ha dejado de funcionar adecuadamente en la exploración de un aspecto de la naturaleza, hacia 
el cual el mismo paradigma había sido encaminado. En este sentido, en ambas revoluciones el mal funcionamiento ocasiona una crisis que obliga a una transformación de las instituciones existentes.

La noción de infancia como institución tiene un carácter especial, debido al largo proceso de construcción conceptual que ha sufrido en el transcurso de su historia. Así, su concepción se ha ido transformando conforme al contexto cultural de la época, en sus inicios como objeto de derechos ${ }^{3}$ hasta luego convertirse en sujeto de derechos. Según Piedrahita (2004), los principios de organización religiosa y militar presentes en períodos como el siglo XII y XIII dan origen a los "niños de las cruzadas"; luego en el siglo XV la niñez se concibe como algo indefenso y, por ello, debe estar al cuidado de alguien, se la defiende, así, como "propiedad". Según Jaramillo (2008), para el siglo XVI ya la concepción de niño es de un ser humano, pero inacabado: "el niño como adulto pequeño". Los principios de organización educativa y científica del siglo XVII y XVIII dan origen al niño escolar y se le da la categoría de infante; pero con la condición de que aún le falta para ser alguien; es el infante como "ser primitivo". De acuerdo con el historiador francés Philippe Ariès (1987), la antigua sociedad tradicional occidental no podía representar bien al niño, y menos todavía al adolescente; así, “... la duración de la infancia se reducía al período de su mayor fragilidad, cuando la cría del hombre no podía valerse por sí misma; en cuanto podía desenvolverse físicamente, se le mezclaba rápidamente con los adultos, con quienes compartía sus trabajos y juegos" (Piedrahita, 2004, p. 6).

Los principios de organización familiar dan origen al hijo de familia que realiza todas sus actividades en el hogar bajo la tutela de los padres. El fortalecimiento del Estado da origen a los hijos del Estado, niños que desde muy pequeños pasan de manos de sus padres a las de un personal especializado que se hace cargo de ellos en guarderías y jardines infantiles, como se ve actualmente. Esta misma situación se observa en las instituciones que se encargan de la protección del niño: de instituciones masivas tipo cuartel o convento se pasa a la institución escuela, institución taller o institución hogar. (Piedrahita, 2004, p. 2)

Sin embargo, de acuerdo con Jaramillo (2008), la "reinvención" moderna de la infancia se inicia desde el siglo XVIII en las sociedades democráticas y, muy especialmente, a través del filósofo francés Jean Jacques Rousseau, quien advertía sobre las características especiales de la infancia. Rousseau (1982) sostiene que se debe asignar un espacio al ser humano (adulto) y otro al niño, otorgarle al ser adulto

3 Una de las características del antiguo paradigma (modelo tutelar) es que los "menores" son considerados objetos de protección, seres incompletos e incapaces que requieren de una atención especial. 
aquello que es propio del ser adulto, y a la niñez aquello que le pertenece como tal. Con respecto a este punto, "El Emilio" se pregunta: “... ¿ por qué el hombre rompe con esta regla? La naturaleza quiere que los niños sean niños antes que sean hombres, por esta misma razón la infancia es parte de ella, es un escalón necesario y anterior a la adultez" (Rousseau, 1982, p. 97). Así también, para Ariès (1987), el concepto de infancia fue inventada o descubierta entre fines del siglo XVII e inicios del XVIII, conforme un análisis de obras de arte medieval y renacentista. Igualmente, Lloyd deMause (1982) coincide en que en este período histórico que da inicio el concepto de infancia, aunque se diferencia de Ariès, debido a que su tesis postula una visión optimista que se contrapone a la perspectiva más nostálgica y pesimista de Ariès, quien considera la existencia de un control creciente sobre la infancia en relación con su libertad. Del mismo modo, Hugh Cunningham (2006) considera que en el siglo XVIII comienza a ser dominante una visión secular de la infancia, donde empiezan a operarse cambios significativos tanto en la conceptualización de la infancia como en el trato hacia la niñez.

A partir del siglo XX, debido principalmente a las acciones y movimientos a favor de la infancia, se reconoce una nueva categoría: "el niño como sujeto de derecho". Este movimiento empieza a concebir la infancia como una categoría que encierra un mundo de experiencias y expectativas distintas a las del mundo adulto. Es así como a partir de la CDN, aprobada por la Asamblea General de las Naciones Unidas el 20 de noviembre de 1989, se le define como un sujeto de derecho, reconociendo en la infancia el estatus de persona. De esta manera, el largo proceso de construcción social de la infancia puede ser caracterizado por una una serie de negaciones y limitaciones a la condición humana, a fin de "proteger" la convivencia de las personas adultas y resguardar el statu quo dentro de la sociedad. Así, la CDN aparece como instrumento jurídico revolucionario que rompe con la hegemonía adulta sobre la infancia, al menos jurídicamente, para otorgar derechos y libertades a los grupos de NNA.

Según Kuhn (1971), las revoluciones políticas tienden a cambiar las instituciones en modos que esas mismas instituciones prohíben, porque su éxito exige el abandono parcial de una en favor de la otra, permitiendo que los individuos se comprometan con alguna propuesta concreta para reconstruir la sociedad en función de una nueva estructura institucional. Este cambio de paradigma en la infancia, que reúne los componentes histórico-consensual-prescriptivo, aún continúa en un proceso de transición desde la doctrina de la situación irregular (el niño y la niña como objeto de derecho) hacia una doctrina de la protección integral (el niño y la niña como sujeto de derecho), debido a que los grupos miembros de la sociedad, quienes de alguna manera construyen el imaginario colectivo aún se encuentran 
profundamente vinculados con el antiguo paradigma que mira a la infancia como un grupo de personas incompletas y carentes de todos sus derechos.

La reflexión y el debate sobre los NNA ha sido un proceso silencioso y decisivo para el reconocimiento de los derechos de la infancia en las sociedades latinoamericanas y para el desarrollo de políticas sociales destinadas a este grupo social. Así vemos cómo se hace visible la actitud de los sujetos adultos frente a la infancia en el curso de la historia, que sigue cambiando, de manera lenta y en ocasiones casi imperceptible.

\section{El nuevo sujeto de derechos}

En la concepción tutelar, las leyes e instituciones que regulaban la situación de la infancia con anterioridad a la CDN pertenecen a lo que se ha denominado en la bibliografía latinoamericana como modelo de "situación irregular". Según Beloff (2009), “... este sistema reproduce criterios criminológicos propios del positivismo de fines del siglo XIX y principios del XX. El determinismo entre pobreza, marginalidad y delincuencia, se encuentra presente en todas las leyes, prácticas e instituciones tutelares" (p. 21). Es decir, la concepción de niñez en el antiguo paradigma viene asociada a la de "menor-abandonado-delincuente". Al respecto:

Se instala y expande en nuestra región latinoamericana bajo el rótulo de una aberración jurídica denominada doctrina de la situación irregular. Una cultura, que con base en la exclusión social la refuerza y legitima introduciendo una dicotomía perversa en el mundo de la infancia. Una cultura, que construye un muro jurídico de profundas consecuencias reales, destinado a separar niños y adolescentes de los otros, los menores a quienes construye como una suerte de categoría residual y excrecencia respecto del mundo de la infancia. (García, 1997, p. 2)

Así, en la doctrina de la situación irregular los grupos de NNA eran considerados como un asunto de familia o un problema del Estado, este último cuando estaban en conflicto con la ley o se encontraban fuera del grupo familiar. De esta manera, los derechos de NNA dentro de la familia o ámbito privado eran desconocidos o supeditados a los "derechos de los padres", y los derechos de quienes estaban en el ámbito público fuera de un grupo familiar o en conflicto con la ley, tenía apenas un carácter proteccionista que consideraba que debían institucionalizarse en orfanatos, cárceles o cuarteles, para "protegerlos" y "proteger" a la sociedad. Según Beloff (2009), esta concepción de protección a la que se somete a "menores" con frecuencia viola o restringe derechos, precisamente porque no está pensada

4 En las legislaciones anteriores a la CDN, el término "menor" era utilizado para denominar a NNA en situación irregular, en condiciones de pobreza, abandonados, inadaptados e infractores. 
desde la perspectiva de los derechos, como acción estatal dirigida a garantizar los derechos de los grupos de NNA. Esta concepción se constituye a partir de una definición negativa de los niños y las niñas como actores sociales, basada en lo que "no saben", "no tienen" o "no son capaces".

Sin embargo, este modelo comenzó a ser erradicado en Latinoamérica por Brasil, luego de la promulgación de la Ley 8069/90 (Estatuto del Niño y del Adolescente), con lo cual se convierte en el primer país de la región en proceder a la adecuación sustancial de su legislación conforme a la CDN. Con ella, se instala un modelo de protección integral que se apoya en bases conceptuales antagónicas a las de la doctrina de la situación irregular. En consecuencia, Señala Beloff (2009):

Los niños son ahora definidos de manera afirmativa, como sujetos plenos de derecho. Ya no se trata de menores, incapaces, personas a medias o incompletas, sino de personas cuya única particularidad es estar creciendo. Por eso se les reconocen todos los derechos que tienen los adultos, más derechos específicos precisamente por reconocerse esa circunstancia evolutiva ... El reconocimiento y promoción de los derechos de los niños se produce en una concepción integral que recupera la universalidad de la categoría de la infancia, antes fragmentada por las leyes de menores. (p. 35)

Por tanto, el conjunto de derechos contenidos en la CDN no realiza ningún tipo de distinción entre NNA, sino, al contrario, unifica al mundo de la infancia que se encontraba históricamente dividida. Entre ellos, el derecho de la persona menor de edad a ser oída y que sus opiniones sean tenidas en cuenta, afirman la libertad de expresión de los nuevos sujetos de derechos, en cualquier ámbito que se desenvuelvan, inclusive ante las instituciones de justicia 5 .

Ahora bien, puede resultar fácil hablar o teorizar acerca de los derechos que tienen NNA, sobre el concepto de niño, niña o adolescente como sujeto de derecho, sobre el derecho que tienen a ser oídos, sobre su derecho a la intimidad, sin embargo, cuando debemos poner en práctica los alcances de estos derechos no resulta tan sencillo. Muchas veces, en los ámbitos de actuación, no se reconoce a NNA como sujetos de derecho, con lo que ello implica, que no estamos acostumbrados a pensar que un niño es una persona, un ser humano distinto a las personas adultas y que merece ser tratado con dignidad, en cuanto a sus derechos como ser humano. Porque como señala Rousseau (1982), “... la infancia tiene maneras de ver, de pensar, de sentir, que le son propias; no hay nada más insensato que quererlas sustituir por las nuestras; tanto equivale exigir que un niño tenga cinco pies de alto que juicio a los diez años" (p. 47).

5 Al respecto: CDN, 1989, artículo 12.

$68 \begin{aligned} & \text { Revista Latinoamericana de Derechos Humanos } \\ & \text { Volumen } 30 \text { (2), II Semestre 2019 } \\ & \text { ISSN: 1659-4304 - EISSN: 2215-4221 }\end{aligned}$ 
La condición de "evolución" y "crecimiento", en que se encuentra la niñez, no justifica, de manera alguna, el no reconocimiento o limitación de derechos, sino al contrario, implica comprender los derechos humanos como un proceso constante de construcción de ciudadanía, que se expresa en la fórmula de reconocimiento del "derecho a tener derechos" (Cillero, 1997, p. 3). Sin embargo, la transición de un modelo a otro no ha significado un proceso corto y simple, debido a que el escenario donde acontece este cambio de paradigma no es un espacio nuevo; al contrario, es un lugar donde existe toda una estructura que fue construida desde hace siglos y que precisa ser derribada para levantar una nueva.

Aunque a primera vista pueda parecernos escandaloso, parece que el imaginario colectivo se resiste a creer que también (los niños) forman parte de la categoría de seres humanos. Este imaginario se hace transparente en el ámbito internacional. Aun existiendo tratados internacionales sobre Derechos Humanos, en dicho ámbito han persistido, y todavía persisten serias dudas acerca de que puedan incluirse en ellos a los niños y niñas. (Casas, 1998, p. 218)

\section{La infancia como "Futura ciudadanía"}

Uno de los objetivos de la participación en un sistema democrático es la "realización de ciudadanía", constituyéndose en una de las conquistas más importantes de la historia (Demo, 1941), aunque presente complejidades en cuanto a su formación y evolución. El desarrollo del concepto se circunscribe a aquel que define al sujeto ciudadano formal como miembro de un Estado-nación, de un sujeto ciudadano como poseedor de derechos civiles, políticos y sociales. Rawls (1995) afirma:
El ideal de la ciudadanía impone un deber moral (no legal) -el deber de la civilidad- para poder explicarse unos a otros, acerca de esas cuestiones fundamentales, cómo los principios y las políticas que preconizan y por las que votan pueden apoyarse en los valores políticos de la razón pública. Este deber también implica la disposición a escuchar a los demás y a actuar con mentalidad de imparcialidad, de apego a lo justo, al decidir cuándo han de hacer ajustes, razonablemente, para conciliar sus propios puntos de vista con los de sus conciudadanos. (p. 208)

Para Rawls (1995), la democracia implica una relación política entre sujetos ciudadanos dentro de la estructura básica de la sociedad, que trae consigo la participación en igualdad dentro del poder político coercitivo que ejercen unos sobre otros, como, por ejemplo, mediante el voto. No obstante, mediante el ideal de "razón pública", el ciudadano es quien suscribe un determinado conjunto de principios y no lo concibe necesariamente como participante activo de la política. Tanto es así que la división entre ciudadanía políticamente activa y el resto de la 
población es una realidad dentro de la sociedad, debido a diferentes motivos, lo que resulta congruente con la libertad individual de obrar de cada quien sin que esto represente una pérdida de igualdad ante la ley.

Al respecto, Habermas (1999) aporta un pensamiento liberal del estatus de ciudadano o ciudadana, determinado por la medida de los derechos subjetivos que se tiene frente al Estado y frente a las demás personas ciudadanas:

Como sujetos portadores de derechos subjetivos, disfrutan de la protección del Estado mientras persigan sus intereses privados dentro de los límites trazados por la leyes, incluida, al mismo tiempo, la protección frente a las actuaciones estatales que vayan más allá de las reservas legales de intervención. (Habermas, 1999, pp. 232-233)

En este sentido, se incide sobre el contenido racional de una filosofía moral basada en el respeto igualitario para cada sujeto ciudadano y de la responsabilidad universal de cada persona para con la otra. Pero, ¿cómo se logra ese reconocimiento ciudadano de un sector que históricamente ha sido excluido de la sociedad? Al respecto, Habermas (1998, p. 43) sostiene que el reconocimiento nace a partir de la realización consecuente de la declaración de los derechos individuales.

Si bien es cierto que los grupos y subculturas se integran desde una perspectiva ética con su respectiva identidad colectiva, la integración política se realiza en una esfera más abstracta, como inclusión ciudadana, lo que implica no solo una integración de tipo formal, sino moral, dado que las normas jurídicas tienen esa cualidad.

El problema se plantea también en las sociedades democráticas cuando la cultura mayoritaria políticamente dominante impone su forma de vida y con ello fracasa la igualdad de derechos efectiva de ciudadanos con otra procedencia cultural. Esto tiene que ver con cuestiones políticas que afectan a la autocomprensión ética y la identidad de los ciudadanos. (Habermas, 1999, p. 123)

Siguiendo a Habermas, el fundamento de la "inclusión del otro", y por consiguiente de la ciudadanía, es la forma de consenso respecto a los procedimientos que nos presentan los principios universalistas del Estado de derecho. Estos incluyen lo que el citado autor denomina la "cultura política de los principios democráticos", que se manifiesta en el llamado patriotismo de la Constitución (Habermas, 1998, p. 264). Entonces, se considera que la inclusión del "otro" debe comprenderse en relación con la noción de ciudadanía (que se vincula a una cultura política universalista), que al mismo tiempo no puede sobrepasar los derechos individuales de la ciudadanía, plasmados en los derechos humanos, fundamento del Estado de derecho democrático. 
El desafío será mayor cuanto más profundas sean las diferencias religiosas, raciales o étnicas, o los desfases históricos-culturales que deben ser superados; será tanto más doloroso cuanto más las tendencias a auto-alrmarse asuman un carácter fundamentalista que tienda a poner límites, ya sea porque la minoría que lucha por su reconocimiento, producto de su experiencia de impotencia, se bate en retirada, o porque, en primer lugar, debe despertar la conciencia a través de la movilización de masas. (Habermas, 1999, p.160)

Para este autor, el problema de las identidades individuales siempre está vinculado con las identidades colectivas, las cuales logran su equilibrio a partir de una red cultural cohesionada, que no es otra que una cultura política que debe dar cuenta del bien común. Como señala él mismo:

La coexistencia en igualdad de derechos de diferentes comunidades étnicas, grupos lingüísticos, confesiones y formas de vida no puede conseguirse al precio de la fragmentación de la sociedad; el doloroso proceso de desacoplamiento no puede desgarrar a la sociedad en una pluralidad de subculturas que se aíslen unas de otras. Es decir, la cultura mayoritaria tiene que desprenderse de su fusión con la cultura política general, compartida en igual grado por todos los ciudadanos. (Habermas, 1989, pp.174-175)

Este desprendimiento de la cultura mayoritaria es la escisión que debe producirse dentro de la sociedad para la incorporación de grupos o sectores aislados. Conforme a estas directrices de ciudadanía dentro de una sociedad democrática, la infancia como grupo socialmente excluido inicia su proceso de acercamiento al concepto de ciudadanía a partir de un instrumento específico que consagra sus derechos humanos. En este sentido, la CDN diseña las bases para la construcción plena de la ciudadanía, pero que debe superar cuestiones relacionadas a la "incapacidad" y la "minoría", vestigios del antiguo paradigma, colocados por el sector mayoritario de la sociedad (sector adulto) para evitar el acceso pleno de los NNA a la concepción de ciudadanía.

Un orden jurídico no solo tiene que garantizar que cada persona sea reconocida en sus derechos por todas las demás personas; sino que el reconocimiento recíproco de los derechos de cada uno por todos los demás tiene que descansar en leyes que serán legítimas en la medida en que se garanticen iguales libertades a todos, de suerte que "la libertad del arbitrio de cada uno sea compatible con la libertad de cada uno de los demás". (Habermas, 1998, p. 94)

Asimismo, existen representaciones sociales sobre la infancia, que la configuran como una población formada por seres humanos fundamentalmente distintos e inferiores a las personas adultas, como señala Casas (2006), los "aún-no". En el 
imaginario social-colectivo, no se piensa que los sujetos menores de edad puedan ser iguales a las personas adultas, es decir, que puedan tener los mismos derechos y se encuentren dentro del mismo estatus de personas. Al contrario, el valor social de la infancia está en el futuro, por tanto, los grupos de NNA son "futuras personas adultas", "futuros sujetos ciudadanos", de nuestra "sociedad del futuro". Esta imagen de la infancia como futura ciudadanía, nuevamente nos traslada al antiguo paradigma, donde quien está en la niñez es una persona incompleta o inacabada que precisa de protección especial para asegurar el "futuro de la sociedad" de acuerdo con la visión de las personas adultas en ese momento histórico determinado.

A partir de esta representación social, además de negar a la infancia sus derechos de ciudadanía, la misma también es sometida durante su proceso evolutivo a un conjunto de reglas y condiciones para preservar el statu quo. Esta negación del mundo adulto, que coloca a NNA dentro de cajas perfectamente moldeadas, se convierte, posteriormente, en inquisidora cuando los "futuros ciudadanos" se alejan de los padrones establecidos, creando una quiebre generacional que castiga y oprime a los grupos NNA y los conceptualiza como "rebeldes al sistema" para luego culparlos del mal funcionamiento de la sociedad. Esto se produce, porque para la "ciudadanía del presente" los NNA pertenecen al entorno privado (familia) y en algunos casos del Estado (escuelas, correccionales); pero no a la sociedad, porque aún no forman parte de ese colectivo, "aún no están preparados" para ser ciudadanos o ciudadanas. En este escenario, pensar en los grupos de NNA como ciudadanos del presente constituye una labor inconclusa del nuevo paradigma y continúa siendo el último bastión del antiguo paradigma.

Sobre la inclusión de grupos sociales excluidos:

Una nación de ciudadanos se compone de personas que a consecuencia de sus procesos de socialización encarnan al mismo tiempo las formas de vida en las que se ha formado su identidad, incluso cuando de adultos se han separado de sus tradiciones de procedencia. (Habermas, 1999, p. 124)

Para Habermas, existe una conciencia deliberativa ciudadana vinculada en el respeto a la soberanía popular y a los derechos humanos. Esa conciencia deliberativa que nace de la solidaridad abstracta y jurídicamente construida es reproducida en un sistema profundamente democrático. Así, la solidaridad ocupa un lugar destacado en la acción comunicativa, donde los individuos se reconocen como sujetos libres, solidarios y con competencia, por el estatus de ciudadanos que poseen, lo que les permite fundamentar y responder acerca de las situaciones que les afectan. En este sentido, los sujetos ciudadanos se aceptan recíprocamente como iguales 
sin señalar o imponer restricciones sobre la condición humana de alguno de los grupos que integran la sociedad.

\section{La autonomía progresiva: El camino hacia la ciudadanía}

El camino de la infancia en la sociedad democrática puede ser caracterizado por una lucha contra la negación de su condición de persona. La exclusión de los NNA en el pacto social se hace visible en la imposibilidad para el ejercicio de sus derechos ciudadanos, que garantiza a todos los seres humanos el acceso a los derechos civiles y de libertad, según lo establecido en las declaraciones de derechos humanos. En este sentido, la lucha por la igualdad de derechos está fundada en el reconocimiento de su diferencia como grupo social dentro de la sociedad ${ }^{6}$. Acerca de la concepción de ciudadanía, esta puede ser entendida también como:

El estado jurídico de plena participación en la comunidad estatal y en los otros entes políticos territoriales. En su forma integral ella supone la vigencia, de derecho y de hecho, de principios y normas constitucionales propias del Estado social y democrático de derecho, y la titularidad de todos los derechos fundamentales que caracterizan esta forma de Estado, incluyendo aquellos políticos y de participación política. (Baratta, 1998, p. 30)

La CDN ha sido el instrumento jurídico generador de este cambio de paradigma que comenzó a colocar a la infancia dentro de la sociedad, lugar de que ha sido históricamente excluida. Este instrumento universal se estructura a partir de algunos principios como: interés superior del niño y la niña, no discriminación, protección integral, participación y autonomía progresiva; que se encuentran explícitos en los primeros artículos del citado ordenamiento legal. Estos principios son proposiciones que describen derechos tales como: igualdad, protección efectiva, autonomía, libertad de expresión, participación, entre otras; cuyo cumplimiento es una exigencia de la justicia. Según Dworkin (1984), la característica principal de estos estándares jurídicos, que aquí se denominan principios, es que cuentan con una dimensión de peso o importancia de los cuales carecen las normas.

Llamo "principio" a un estándar que ha de ser observado, no porque favorezca o asegure una situación económica, política o social que se considera deseable, sino porque es una exigencia de la justicia, la equidad o alguna otra dimensión de la moralidad. (Dworkin, 1984, p.72)

$6 \mathrm{Al}$ respecto, la $\mathrm{CDN}$ en el párrafo $1^{\circ}$ de su preámbulo señala: “... Considerando que, de conformidad con los principios proclamados en la Carta de las Naciones Unidas, la libertad, la justicia y la paz en el mundo se basan en el reconocimiento de la dignidad intrínseca y de los derechos iguales e inalienables de todos los miembros de la familia humana ..." 
En este sentido, la CDN representa un nuevo paradigma en cuanto a los derechos de NNA frente al Estado y las instituciones, estableciendo su inserción en las estructuras y procedimientos de los asuntos públicos. Así, este instrumento actúa como ordenador de las relaciones entre NNA, Estado y familia. Para alcanzar este cometido, los principios mencionados más arriba actúan como reguladores de esta relación; tres de esos principios son los que introducen propiamente ese cambio de paradigma estableciendo un límite a las decisiones que las personas adultas toman sobre niños, niñas y adolescentes: interés superior de la persona menor de edad, protección integral y autonomía progresiva.

Así, la CDN está profundamente ligada a la doctrina de derechos humanos, que no diferencia sujetos entre sí, sino expone los atributos positivos comunes y esenciales de toda persona, declarando sus derechos fundamentales que deben ser reconocidos por su simple condición de persona, es decir, por el solo hecho de existir, sin considerar la edad, el sexo u alguna condición específica. En este sentido, la concepción de NNA como sujeto de derecho supone la idea de igualdad jurídica, es decir, todas las personas son destinatarias de normas jurídicas y tienen capacidad de ser titulares de derechos; esto implica igualdad de derechos ante la ley. Sin embargo, aquí se tiene, además, un sujeto de derecho especialísimo, dotado de una supra-protección o protección complementaria, que se desprende de la necesidad de una protección integral conforme los principios fundamentales citados más arriba.

De esta forma, el grupo de CNN deja de ser objeto de protección y se convierte en sujeto de derecho. A partir de este nuevo paradigma, surge la paradoja de que, si bien el niños, niñas y adolescentes son portadores de derechos y se les reconoce capacidad para ejercerlos por sí, los ordenamientos jurídicos internos no les adjudican una autonomía plena, debido a consideraciones de hecho, relacionadas con su madurez, y jurídicas, referidas a la construcción jurídica tradicional de los NNA como personas dependientes de otros sujetos "adultos" (padres, madres, sujetos tutores, Estado).

$\mathrm{Al}$ respecto, el artículo quinto de la CDN considera y propone un modo de resolver esta situación fáctica y normativa, al disponer que el ejercicio de los derechos de la niñez es progresivo en virtud de la evolución de sus facultades, y que a los padres o responsables en su caso, les corresponde impartir orientación y dirección apropiada para que los NNA ejerzan sus derechos reconocidos en el ordenamiento jurídico. De la misma manera, este principio hace referencia a cómo un ciudadano empieza a ejercer sus derechos de manera gradual, de acuerdo con la evolución de sus facultades. En este sentido, no estamos hablando de un grupo de personas ajenas al concepto de ciudadanía por la simple negación de derechos civiles y políticos, sino que nos encontramos ante un nuevo sujeto de derecho 
que comienza a poner en ejercicio los derechos que le fueron reconocidos por su condición de persona humana.

Los Estados Partes garantizarán al niño que esté en condiciones de formarse un juicio propio el derecho de expresar su opinión libremente en todos los asuntos que afectan al niño, teniéndose debidamente en cuenta las opiniones del niño, en función de la edad y madurez del niño. (CDN, 1989, artículo 12)

Por tal motivo, los principios fundamentales sobre los derechos de la infancia no desconocen que los NNA, en algunas situaciones, no puedan ejercer por sí sus derechos. Sino al contrario, previendo dichas situaciones, obliga al Estado a crear condiciones favorables para que los NNA alcancen su grado máximo de autodeterminación y puedan participar en sociedad. La CDN sostiene que el Estado debe impartir dirección y orientación apropiada para que los NNA ejerzan sus derechos, reconociendo que forman parte de la sociedad. En cuanto a la condición de ciudadano, esta no puede verse limitada por la falta de autodeterminación en algunas circunstancias, ya que el Estado es el encargado de contribuir al desarrollo de la autonomía progresiva de los NNA. De la misma manera, no es posible otorgar autonomía plena a un niño sin considerar sus condiciones evolutivas, ya que eso implicaría dejarlo en un estado de desprotección.

En suma, el principio de autonomía revela que son los NNA quienes deben ejercer sus derechos de acuerdo con la edad y grado de madurez, con el debido acompañamiento de las personas adultas (familia-Estado). Es decir, la toma de decisiones sobre la vida de los NNA deberá variar gradualmente de acuerdo con la evolución de sus facultades. En consecuencia, a medida que los NNA adquieren mayor autonomía, menor es la intensidad de la participación de un tercero para el ejercicio de sus derechos.

Puede decirse, entonces, que el camino de la infancia hacia la ciudadanía es un proceso lleno de limitaciones y dificultades establecidas desde las normas positivas nacionales que, pese a estar basadas e inspiradas en principios universalmente reconocidos y aceptados, dentro de los ordenamientos internos han dado cabida a una serie de interpretaciones restrictivas para negar el reconocimiento de los NNA como ciudadanos libres.

Los principios tienen una dimensión que faltan en las normas: la dimensión del peso o importancia. Cuando los principios se interfieren, quien debe resolver el conflicto tiene que tener en cuenta el peso relativo de cada uno. En esto no puede haber, por cierto, una mediación exacta, y el juicio respecto de si un principio o directriz en particular es más importante que otro será con frecuencia motivo de controversia. 
Sin embargo, esa parte esencial del concepto de principio el que tenga esta dimensión, que tenga sentido preguntar qué importancia o qué peso tiene. Las normas no tienen esta dimensión. (Dworkin, 1984, pp.77-78)

Y es precisamente sobre esta libertad, principio fundamental de la condición humana y base de las constituciones contemporáneas, que la CDN se sirve para reconocer a la niñez todos los derechos cuyo ejercicio constituye la condición para el ejercicio de sus derechos políticos y de participación, así como el de las personas adultas.

Reconociendo que las Naciones Unidas han proclamado y acordado en la Declaración Universal de Derechos Humanos y en los pactos internacionales de derechos humanos, que toda persona tiene todos los derechos y libertades enunciados en ellos, sin distinción alguna, por motivos de raza, color, sexo, idioma, religión, opinión política o de otra índole, origen nacional o social, posición económica, nacimiento o cualquier otra condición. (CDN, 1989, párr. 3 del preámbulo)

La forma en que está construida la ciudadanía del NNA en el sistema de la CDN es lo que lo diferencia de las personas adultas, sobre todo debido a su condición especial de persona en fase de desarrollo que descansa en la protección integral. Esta diferencia, interpretada en "falta de madurez física y mental" es la comúnmente utilizada por los ordenamientos positivos nacionales para fundamentar la negación de ciudadanía del NNA. Mediante esta concepción, dentro de un Estado democrático, se genera una restricción a la participación de estos nuevos sujetos de derecho, en lugar de existir una participación diferenciada para evitar la exclusión de grupos en la sociedad. En este sentido, cuando la norma se aleja del principio, crea una categoría de ciudadanía con un grado mayor de participación y otra con un menor grado de participación.

La superación del concepto de libertad sobre aquella base limitada establecida por las normas se hace necesaria para eliminar la asimetría existente entre los NNA y los sujetos adultos. La ciudadanía es expresión de libertad, que lleva implícito el derecho a ser escuchada y la participación en los asuntos que le involucra e interesa. Para ello, es necesario siempre retomar el concepto de autonomía progresiva del NNA, para entender las complejidades de la infancia como sujeto de derechos, y retomar el camino que permita avanzar hacia la igualdad de derechos para una sociedad más democrática.

\section{Consideraciones finales}

Los nuevos paradigmas nacen de los antiguos, incorporando ordinariamente gran parte del vocabulario y de los aparatos, tanto conceptuales como de manipulación, 
que previamente empleó el paradigma tradicional. Sin embargo, para llevar a cabo la transición entre inconmensurables como él denomina, es necesario establecer nuevas estructuras para sostener y justificar el advenimiento de un nuevo paradigma.

Precisamente porque es una transición entre inconmensurables, la transición entre paradigmas en competencia no puede llevarse a cabo paso a paso, forzada por la lógica y la experiencia neutral. Como el cambio de forma (Gestalt), debe tener lugar de una sola vez (aunque no necesariamente en un instante) o no ocurrir en absoluto. Entonces, ¿cómo llegan los científicos a hacer esta trasposición? Parte de la respuesta es que con mucha frecuencia no la hacen. (Kuhn, 1971, pp. 233-234)

Durante la transición, la resistencia es inevitable y a veces requiere de toda una generación para que el cambio se lleve a cabo. Así también, debe existir una base o fundamento que permita ubicar al nuevo paradigma e ir avanzando de modo gradual, debido a que la simple crisis dada de manera aislada no es suficiente para iniciar una transición hacia el cambio que, como se ha mencionado al inicio, lleva implícito un aspecto histórico, consensual y prescriptivo.

En este contexto, la revolución francesa marcó un precedente importante para la concepción del ser humano en la sociedad, en la cual se estableció que sus derechos se refieren a aquellos derechos inherentes a la persona humana. Sin embargo, los derechos de la ciudadanía implican adicionalmente un determinado status político-jurídico que significa la capacidad plena para ejercer la titularidad activa de los derechos de la persona. En esta concepción, todos los ciudadanos son personas, pero no todas las personas son ciudadanos. Los NNA y hasta no hace mucho tiempo, también las mujeres, formaban parte de esta categoría de no persona, a la cual corresponde un no derecho.

En el caso de los NNA como se ha analizado, eran parte de un sistema denominado de situación irregular, que desde la concepción de menor fue instalándose en la sociedad como una cultura negadora de derechos. No obstante, fue con el advenimiento de la $\mathrm{CDN}$, que puede decirse que se dio una verdadera revolución para el mundo de la infancia. Una revolución que se produjo hace apenas treinta años, pero que permitió a niños, niñas y adolescentes ser transformados en personas para luego adquirir un estatus dentro de la sociedad como portadores de derechos. En el escenario latinoamericano, fue Brasil el país que inició esta revolución, desatando un proceso absolutamente inédito en la tradición socio-jurídica de la región, que otorga nuevos derecho para la infancia ${ }^{7}$. Sin embargo, a pesar de contar con un reconocimiento de derechos, los NNA continúan siendo considerados como

7 La incorporación a la nueva Constitución brasileña (1988), de dos artículos claves para el desarrollo de un nuevo tipo de política social para la infancia: la política social pública (artículo 227 y 204). 
"futuros ciudadanos", constituyendo un resabio del antiguo paradigma fundado en la negación de derechos inherentes a su condición de persona humana.

Por consiguiente, se continúa afirmando que la noción de ciudadanía está profundamente ligada a la de persona adulta sujeto de derecho, manteniéndose alejada de la concepción de niño sujeto de derecho. El camino hacia la ciudadanía y, por consiguiente, hacia la inclusión, forma parte de la transición inacabada hacia el nuevo paradigma, tarea pendiente del Estado para consagrar el estatus de personas de los NNA dentro de la sociedad. Dicha importancia radica en la inclusión de todos los grupos sociales dentro del Estado democrático de derecho. Así como lo menciona Habermas (1999): la inclusión del "otro" como ciudadano constituye el fundamento de un Estado democrático con bases sustentadas en principios universales de derechos humanos.

El argumento construido por la resistencia se ampara en normas negadoras de derechos, tales como consideraciones de hecho, relacionadas con la madurez, y jurídicas, relacionadas con la imposibilidad de realizar actos jurídicos por sí mismos. Para superar esta limitación, fueron tomados como punto de partida los principios establecidos en la CDN, en la que se encuentran las normas de derecho para la infancia, que a su vez descansan en principios fundamentales de derechos humanos universales. En este mismo, se puede determinar cómo en lugar de buscar diferenciar sujetos, solo se señalan, estrictamente, los atributos positivos comunes de toda persona, declarando los derechos fundamentales que le deben ser reconocidos por el solo hecho de existir, sin considerar su edad, sexo u otra condición.

Dentro de una sociedad democrática, el concepto de ciudadanía adquiere un valor de gran relevancia; de hecho, es difícil intentar concebir una sociedad democrática sin que exista ciudadanía. Al respecto, cuando se hace referencia a sujetos ciudadanos que gozan de sus derechos y actúan de manera libre, la participación o el ejercicio de sus derechos no queda supeditada a la condición de persona perteneciente a un grupo determinado de la sociedad. Eso es así porque las limitaciones impuestas constituirían negaciones de derecho y también de ciudadanía. No obstante, la condición de ciudadanía construida por las democracias occidentales dentro de sus ordenamientos jurídicos internos se ha encargado de poner límites a la ciudadanía de los NNA, ubicándolos en una categoría de futuros ciudadanos, equivalente a no ciudadanos.

Sobre el desarrollo de la democracia en las sociedades occidentales, explica Baratta (1998) que esta misma puede ser considerada como un pacto de exclusión, porque en la realidad, a pesar de la trascendencia de los principios universales inherentes a la condición humana que se enuncian en los ordenamientos jurídicos, esta ha 
constituido un pacto entre individuos del género masculino, adultos, blancos y propietarios, para excluir del ejercicio de la ciudadanía en el Estado a mujeres, niños, personas negras, indígenas y desposeídas. Esto ha dado como resultado que el pacto social dentro de las sociedades occidentales esté fuertemente marcado por la lucha de los sectores excluidos, quienes buscan lograr su integración en la sociedad y adquirir el estatus de ciudadanía para convertirse en personas sujetos de derecho que viven en un Estado democrático.

Ante este escenario, es innegable que el nuevo paradigma de la infancia ha significado un cambio sustancial en el campo del derecho y ha posibilitado la adquisición del status de persona por parte de los NNA. Sin embargo, al mismo tiempo plantea un desafío consistente en la marcha progresiva hacia la conquista de sus derechos ciudadanos; un desafío que involucra la estructura y el desarrollo de las sociedades democráticas actuales que deben mirar con preocupación y compromiso hacia el futuro. En este sentido, el reconocimiento de los NNA como ciudadanos y ciudadanas del presente lleva consigo una afirmación de la libre condición de la persona humana, lo cual representa dar un paso adelante para la construcción de sociedades más justas, igualitarias y democráticas.

\section{Referencias}

Ariès, P. (1987). El niño y la vida familiar en el Antiguo Régimen. Madrid, España: Taurus editorial.

Baratta, A. (1998: 21-40). Infancia y democracia. En García, E. y Beloff, M. (Org.), Infancia, ley y democracia en América Latina. Análisis crítico del panorama legislativo en el marco de la Convención Internacional sobre los Derechos del Niño (1990-1998) (pp. 21-40). Temis/ Depalma: Colombia.

Beloff, M. (2009). Los derechos del niño en el Sistema Interamericano. Buenos Aires, Argentina: Editores del Puerto.

Cillero, M. (1997) Infancia, autonomía y derechos: Una cuestión de principios. Infancia: Boletín del Instituto Interamericano del Niño - OEA, 234, 1-13.

Casas, F. (1998). Infancia: Perspectivas psicosociales. Barcelona, España: Ediciones Paidós.

Casas, F. (2006). Infancia y representaciones sociales. Política y sociedad, 43(1), $27-42$.

Demo, P. (1996). Participação é conquista. São Paulo, Brazil: Cortez editora.

De Mause, L. (1982). Historia de la infancia. Madrid, España: Alianza Universidad.

Dworkin, R. (1984). Taking Rights Seriously (Marta Guastavino, trad.). Barcelona, España: Editorial Ariel. 
García, E. y Carranza, E. (1990). Infancia, adolescencia y control social en América Latina. Buenos Aires, Argentina: Editorial Depalma.

García, E. y Carranza, E. (1992). Del revés al derecho. La condición jurídica de la infancia en América Latina. Buenos Aires, Argentina: Editorial Galerna.

García, E. (1994). Derecho de la infancia-adolescencia en América Latina: De la situación irregular a la protección integral. Santa Fe de Bogotá, Colombia: Forum Pacis.

García, E. (1997a). Derecho de la infancia adolescencia en América Latina. De la situación irregular a la protección integral. Ibagué, Colombia: Forum Pacis.

García, E. (1997b). Cidadania da Criança: A Revolução Francesa com 200 anos de atraso. Revista Inscrita, 1, 27-32.

García, E. (2015). Infância, lei e democracia: uma questão de justiça. Revista Brasileira Adolescência e Conflitualidade, 8, 1-22.

Habermas, J. (1989). Identidades nacionales y postnacionales. Madrid, España: Editorial Tecnos.

Habermas, J. (1998) Facticidad y validez. Sobre el derecho y el Estado democrático de derecho en términos de teoría del discurso. Madrid, España: Trotta editorial

Habermas, J. (1999). La inclusión del otro. Estudios sobre teoría política. Barcelona, España: Editorial Paidós

Jaramillo, L. (2008). Concepción de infancia. Zona Próxima, (8), 108-123.

Kuhn, T. S. (1971). La estructura de las revoluciones científicas (Agustín Contín, trad.). México: Fondo de Cultura Económica. (Obra original publicada en 1962).

Marshall, T. (1967). Cidadania, classe social e estatus. Rio de Janeiro, Brazil: Editora Zahar.

Naciones Unidas (2006). Convención Internacional sobre los Derechos del Niño: 20 de noviembre de 1989. Madrid, España: UNICEF-Comité Español.

Piedrahita, M. (2004). El “descubrimiento” de la infancia (I): Historia de un sentimiento. Revista Electrónica de Educación y Psicología, 1(1), 1-11.

Rawls, J. (1995). Liberalismo político (Sergio Madero, trad.). México: Fondo de Cultura Económica.

Rousseau, J. (1982). Emilio. Madrid, España: Editorial Edaf.

$80 \mid \begin{aligned} & \text { Revista Latinoamericana de Derechos Humanos } \\ & \text { Volumen } 30 \text { (2), II Semestre 2019 } \\ & \text { ISSN: } 1659-4304 \cdot \text { EISSN: 2215-4221 }\end{aligned}$ 